\title{
Promoting Neurological Recovery in the Post-Acute Stroke Phase: Benefits and Challenges
}

\author{
Dirk M. Hermann ${ }^{\mathrm{a}}$ Michael Chopp ${ }^{\mathrm{b}}$ \\ ${ }^{a}$ Department of Neurology, University Hospital Essen, Essen, Germany; ${ }^{b}$ Department of Neurology, \\ Henry Ford Hospital, Detroit, MI, USA
}

\section{Key Words}

Neuronal plasticity · Angiogenesis · Ageing ·

Hyperlipidemia · Diabetes tion is a critical factor in the success of clinical trials, as patient heterogeneity could mask any potential therapeutic benefits.

(c) 2014 S. Karger AG, Basel

\begin{abstract}
Background: Profound cellular and biochemical remodeling processes occur in the brain following an ischemic stroke, raising the possibility that we may be able to promote neurological recovery by harnessing the brain's endogenous recovery processes with pharmacological or cell-based therapies. There is a compelling body of evidence that cerebral plasticity and neurological recovery can be stimulated in the post-acute ischemic brain in this manner. Summary: This overview of neurorestorative therapies highlights the main challenges in their development, and summarizes the implications of these findings to stroke patients. Key Message: Neurorestorative therapies are a highly promising avenue of treatment for the restitution of neuronal networks damaged by stroke. Clinical Implications: The key supporting data have so far been obtained using in vivo models in animals, underscoring the need to validate these findings in humans. For human studies, several potentially confounding variables should be kept in mind, including age, and the presence of risk factors and comorbidities (such as hyperlipidemia and diabetes). Stroke patients vary considerably in age and genetic background, as well as in the etiology, localization and size of brain infarcts. The choice of patient popula-
\end{abstract}

Following the failure of neuroprotection therapies [1, 2], efforts in stroke research have shifted from the acute to the post-acute stroke phase. Studies in rodents indicate that profound remodeling processes take place in the brain following an ischemic stroke $[3,4]$. This has invigorated hopes that we may be able to promote neurological recovery by means of pharmacological or cell-based therapies. Remodeling of ischemic brain tissue involves interactions between neurons, glial and microvascular cells that create a microenvironment in which neurological recovery may ensue. Neurons and brain capillaries sprout. Neuronal outgrowth enables the formation of functional axons and synapses in the brain both over long (e.g., along pyramidal tract; $[5,6])$ and short (e.g., within motor cortex; $[7,8]$ ) distances, thus allowing for the recruitment and formation of neuronal networks and/or restitution of neuronal networks that were damaged by the stroke event. In the process of brain remodeling, proliferating microvascular cells play a supportive role, enabling the migration of neural precursor cells and promoting the remodeling of neurons and glial cells via secretion of growth factors [3]. This rearrangement of cell-cell interactions is followed by the resti-

\section{KARGER}

E-Mail karger@karger.com

www.karger.com/ene (c) 2014 S. Karger AG, Base

0014-3022/14/0726-0317\$39.50/0
Prof. Dr. Dirk M. Hermann

Department of Neurology

University Hospital Essen

Hufelandstrasse 55, DE-45122 Essen (Germany)

E-Mail dirk.hermann@uk-essen.de 
tution of a functional blood-brain barrier, leading to the recuperation of brain homeostasis $[9,10]$.

Based on promising observations in animal models of ischemic stroke, clinical studies in human patients are currently in progress, the results of which are eagerly awaited. In these studies, plasticity-promoting growth factors (e.g., granulocyte colony-stimulating factor [G$\mathrm{CSF}]$ ), cell-based therapeutics (e.g., multipotent mesenchymal stromal cells [MSC]), neutralizing antibodies directed against axonal growth inhibitors (e.g., NogoA), and pharmacological compounds (e.g., the phosphodiesterase-5 inhibitor sildenafil) are analyzed (reviewed in [4]). While cell-based therapeutics, that is, based on stem and precursor cells of different origin, have initially been used with the aim of cell replacement, it was more recently recognized that the beneficial effects of stem cells depend on paracrine bystander effects, rather than on neuronal differentiation and integration $[6,11]$.

The interactions between neurons, glial cells and microvascular cells are finely tuned. They involve mutual cell communication via the release of growth factors and physical cell-cell interactions across the extracellular matrix that is itself subjected to remodeling processes after stroke [10]. In view of the complexity of these systems, taking into consideration both the structural and functional heterogeneities of brain structures and the heterogeneities of ischemic strokes with respect to their size, etiology, and localization [4], the development of neurorestorative therapies is a formidable challenge. Importantly, it was noted that neurorestorative processes in the adult brain may differ substantially depending on the presence of associated risk factors and comorbidities, and they are also influenced by ageing processes.

In this minireview, we highlight the benefits and challenges of neurorestorative therapies, pointing out ways how future study failures may be circumvented in an ischemic stroke. Minireviews, however, cannot replace the need for thorough literature assessments. For this purpose, the reader is referred to more detailed works of the authors, in which the concepts outlined here are presented in more detail (see references $[3,4,9]$ ).

\section{Benefits of Neurorestorative Therapies}

Neurorestorative therapies can be instituted over extended time windows in the stroke recovery phase. In rodents, beneficial effects on neurological recovery were reported even when treatments were initiated days, weeks, or months after stroke $[5,11-16]$. In sharp contrast to neuroprotection, the efficacy of neurorestorative therapies does not depend on the successful reperfusion of tissue. Thus, neurorestorative therapies are efficacious even under conditions of permanent focal cerebral ischemia $[12,14,17-19]$. In view of the extended therapeutic window, and considering that tissue reperfusion is not a requirement, neurorestorative therapies can potentially be of benefit to all stroke patients.

\section{Effects on Neuronal Plasticity}

Subsequent to the anterograde Wallerian degeneration of injured axons, the surviving proximal axonal segments (i.e., the axon stumps) reorganize along the infarct rim $[19,20]$ and grow out behind the site of injury $[5,21]$. In the pyramidal tracts, the stroke event per se promotes axonal sprouting both ipsilateral $[5,21]$ and contralateral $[8,18,21,22]$ to the stroke. The endogenous responses are enhanced by neurorestorative treatments, which promote the sprouting of pyramidal tract axons originating from the contralesional motor cortex that traverse the midline in order to reach neurons denervated by the stroke $[5,12,14,17,18,21,23]$.

Importantly, this pattern of contralesional long-distance axonal sprouting is relatively uniform for different types of treatment, namely growth factors (e.g., erythropoietin, vascular endothelial growth factor [VEGF]) [5, $21,22]$, neutralizing antibodies directed against the axonal growth inhibitor NogoA [14, 17], neurostimulants (e.g., amphetamine) [24], and cell-based therapeutics, such as neural precursor cells (NPC) [12] and multipotent MSC [18]. Contralesional plasticity as a basis for neurological recovery is observed in rats $[12,14,17]$, mice $[5$, $18,21]$, and macaque monkeys [25]. Stroke-related neuronal plasticity is evident not only in young, but also in aged animals $[14,26,27]$. Thus, in the experimental setting, there is solid evidence for axonal remodeling as a correlate of restorative therapies.

\section{Effects on Angiogenesis}

Following a stroke, angiogenic growth factors are released by neurons and glial cells that induce endothelial proliferation and sprouting [3,28-30]. Acting on VEGF receptor-2 (VEGFR2) that is highly abundant at the tip of new-formed capillaries, VEGF induces endothelial proliferation, and concurrently upregulates the transmembrane ligand Delta-like (Dll)-4, which signals to microvascular cells in the capillary stalk, downregulating VEGFR2 on the stalk cells via interaction with its receptor Notch-1, thus preventing uncontrolled capillary growth $[31,32]$. This lateral inhibition, which is a key principle 
underlying structural development during ontogeny, is recapitulated following ischemia [33-35].

In adolescent mice, VEGF promotes angiogenesis in the ischemic brain [36], elevating regional cerebral blood flow (CBF) during subsequent ischemic episodes, thus stabilizing energy metabolism and preventing secondary brain infarction [37]. Interestingly, whereas VEGF-induced angiogenesis is most pronounced in the vicinity of evolving brain infarcts [36, 37], long-distance pyramidal tract plasticity is mainly induced by VEGF contralateral to the stroke [21, 23]. Hence, neurorestorative treatments induce complex changes within both the vasculature and neuronal networks, setting the stage for neurological recovery processes.

\section{Effects on Neurogenesis}

Neurogenesis is stimulated in response to stroke and is significantly amplified by therapeutic interventions that promote functional recovery [38-41]. Neurogenesis is sustained in the germinal niches in the subventricular zone (SVZ) of the lateral ventricle and the subgranular layer (SGL) of the dentate gyrus that host NPC even during adulthood $[39,40]$. In the event of a stroke, NPC proliferate and migrate in the direction of the ischemic lesion, propagating in chains along blood vessels $[42,43]$.

That NPC promote neurological recovery could be attributed to bystander effects related to the interaction of neuroblasts with the microvasculature in the vicinity of the ischemic lesion, which creates an environment that nurtures and fosters brain remodeling [11, 12, 42, 44]. By the release of trophic factors, microvessels and neuroblasts mutually support each other, resulting in a tight interplay resembling dancers in a tango (fig. 1). In the brain parenchyma, the release of trophic factors reduces delayed neuronal degeneration $[11,43]$, promotes neuronal plasticity [12], modulates glial responses [11, 45], and attenuates inflammatory responses $[11,45]$.

\section{Effects on Glial Cells}

In addition to controlling water shifts within the brain, astrocytes remove excitatory neurotransmitters (e.g., glutamate) and electrolytes (e.g., potassium) from the extracellular space, thus controlling neuronal excitability and plasticity [46]. Subsequent to ischemia, astrocytes secrete lipoproteins, namely apolipoprotein-E, into the perivascular space, thus inducing the ATP-binding cassette transporters, namely the drug efflux transporter ABCB1 [47, 48], contributing to the maintenance of brain homeostasis.

Chondroitin sulfate proteoglycans released by astrocytes and oligodendrocytes create a growth-repulsive microenvironment for axons and dendrites under physiolog-

Neurological Recovery in the Post-Acute Stroke Phase

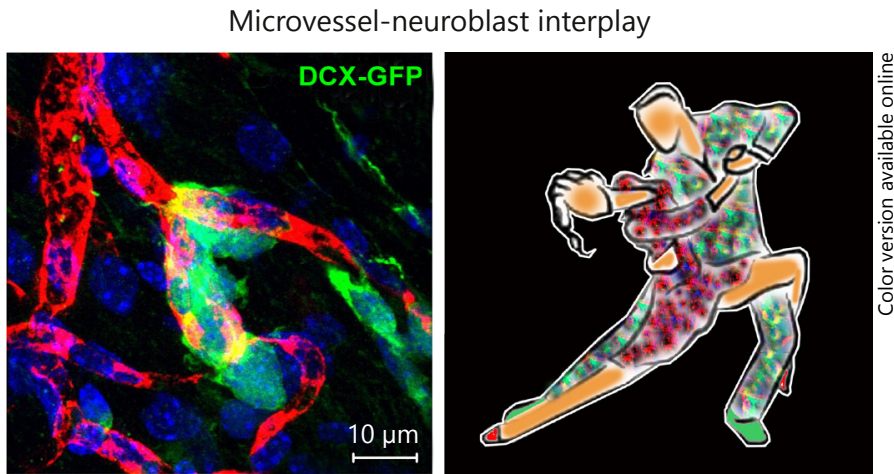

Fig. 1. Interaction of microvascular cells with neuroblasts during post-ischemic brain remodeling. Following ischemia, neuroblasts (see left upper microphotograph: in green [DCX-GFP]) associate with cerebral microvessels (lumen stained in red by systemic injection of rhodamine-labeled dextran prior to animal sacrifice) in a very intimate manner resembling the mutual attraction of dancers in a tango (section counterstained with 4',6-diamidino-2-phenylindole: in blue). Via release of growth and differentiation factors, microvascular cells and neuroblasts foster neuronal survival and plasticity, and modulate glial responses in the brain. DCX-GFP, green fluorescent protein-labeled doublecortin. Bar, $10 \mu \mathrm{m}$. Photomicrograph from reference [4] was translated into a cartoon by Dr. Yi Li (Henry Ford Hospital).

ical conditions [49-51]. Therapeutic interventions promoting axonal plasticity, such as VEGF, and bone marrow stromal cells (BMSC) further decrease the proteoglycan levels $[21,52]$. Post stroke, astrocytes play a major role in mediating brain plasticity and subsequent neurological recovery [53-55]. White matter remodeling in response to BMSC treatment is fostered by astrocytes, which increase tissue-plasminogen activator (tPA) activity $[56,57]$. The sonic hedgehog (Shh) pathway, a major morphogen in brain development [58], which is stimulated after BMSC treatment in astrocytes, affects multiple processes and molecular pathways [59]. Increasing Shh levels permits the expression of Gli transcription factors, which leads to the activation of tPA and likely the generation of other proteins [57, 60-62]. tPA promotes brain plasticity via proteolytic and non-proteolytic pathways $[63,64]$.

\section{Challenges for Neurorestorative Therapies}

While the requirements for brain recovery have been assessed in recent years, the over-whelming majority of studies published were conducted using healthy adolescent rats and mice, which potentially increases the problems in a typical age-related disease such as stroke, in 
which patients exhibit high loads of vascular risk factors and comorbidities. Age itself, similarly to vascular risk factors and vascular diseases, has recently been shown to modulate restorative brain responses, which may result in the loss of therapeutic actions or even evoke detrimental actions that outweigh the therapeutic response. For obvious reasons, such observations have a profound influence on the translation of treatments to human patients, in which such bystander effects carefully need to be taken into account. The following sections summarize the key observations made in aged animals and in animals exhibiting vascular risk factors.

\section{Compromised Brain Remodeling Associated with Age}

Stroke primarily affects humans in advanced stages of their life. Aged individuals recover less well from stroke than young individuals [65]. This may be due to the fact that infarct development and neuronal degeneration are accelerated, as was shown in aged rats when compared with young rats [66]. On the other hand, attenuated brain tissue remodeling may compromise recovery processes. Studies conducted in aged rats have demonstrated that neurological impairment is more severe and functional recovery less successful than in young rats [67-69]. When interpreting these data, it should be kept in mind that aged rats already exhibit reduced performance prior to their stroke, at least in some parameters such as spontaneous activity [70] and Morris water-maze [71] tests, which may explain in part the age-related recovery impairment.

Aged rats respond to plasticity-promoting therapies. Improved neurological recovery associated with the preservation of pyramidal tract axons ipsilateral to the stroke and enhanced pyramidal tract sprouting contralateral to the stroke were found in 25-month-old or 12-month-old ischemic rats treated with neutralizing NogoA antibodies [14], pharmacological compounds [72], or BMSC [26]. In the case of BMSC delivery, neurological improvements persisted in middle-aged rats ( 12 months) for at least one year [26]. Although neurological recovery was successful, dendritic and synaptic plasticity of hippocampal CA3 and CA1 pyramidal and dentate gyrus granule cells were not influenced by NogoA antibodies in aged ( 24 months) rats; yet improvements in spatial memory were present [73]. Indeed, the expression of plasticity-related proteins in neurons differs between young and old animals. Thus, IGF-1 was primarily localized to astrocytes in the peri-infarct cortex of two-month-old rats, but exhibited predominantly as neuronal labeling in two-year-old rats [74]. Lingo- $1 \mathrm{immu-}$ nostaining, in contrast, was stronger in the neurons of older (two years) than young (two months) rats [74].
Specific aspects related to aging were not only observed for neuronal sprouting, but also for neurogenesis and angiogenesis. The number of proliferating NPC in the SVZ and SGL were lower in the brain tissue of 15-month-old than 3-month-old rats, both under physiological and ischemic conditions [75]. Although the de novo generation of neurons in the ischemic striatum was very similar in both groups, neurogenesis was decreased in the dentate gyrus of 15-month-old rats when exposed to focal cerebral ischemia [75]. It has been proposed that the decline in neurogenesis in old animals is related to a reduced expression of VEGF receptor-2 present on the surface of NPC of 2-year-old, but not in 3-month-old or 12-monthold mice [76]. After delivery of an adeno-associated viral VEGF vector, both NPC proliferation and brain capillary formation were compromised in very old mice [76]. The treatment of 18-month-old rats post stroke with sildenafil significantly increased neurogenesis and angiogenesis and also led to the improvement of neurological function [77]. So also, the treatment of 19-20-month-old rats with G-CSF enhanced neurological recovery, cellular proliferation and neurogenesis in ischemic tissue [78].

Astroglial responses to stroke injuries were also influenced by ageing. Shortly after stroke, nestin- and GFAPpositive cells demarcated the infarct core significantly earlier in aged rats than in young rats [79]. Proliferating astrocytes led to the premature glial scar formation in aged rats that presumably limits neurological recovery. It should be noted that there are at least three cell types contributing to the formation of the astroglial scar. Nestinpositive cells are the first to delineate the glial scar in aged rats, becoming visible in the brain on day 3 after focal cerebral ischemia, before GFAP-positive astrocytes (found on day 7) and astrocytes expressing the N-terminal fragment of amyloid precursor protein (APP) (found on day 14) are detectable [80-82]. The precipitous buildup of the astroglial scar is considered to impede axonal growth.

Although existing evidence is limited to a rather small number of studies, the preserved neurological recovery in old animals argues against specific age limits for neurorestorative treatments. Despite this, age aspects need to be controlled in clinical proof-of-concept studies.

Subtle Alterations of Growth Factors, but Intact Brain Remodeling Associated with Arterial Hypertension

Stroke patients exhibit a high prevalence of vascular risk factors. Three out of four stroke patients suffer from arterial hypertension, half of all stroke patients exhibit hypercholesterolemia, and one out of four stroke patients is dia- 
betic $[83,84]$. Experimental studies poorly mimic comorbidities, since experiments are mostly performed in animals that are otherwise healthy. Therefore, the consequences of vascular risk factors for brain remodeling are incompletely understood. In spontaneously hypertensive rats, subtle reductions in brain concentrations of neurotrophic factors and their receptors (namely BDNF, neutrophins-3/4, TrkA, TrkB) have been noted in the dentate gyrus [85]. In focal cerebral ischemia, these alterations did not result in major disturbances of contralesional axonal sprouting in response to neutralizing NogoA antibody treatment, enabling neurological recovery in a way that is very similar to that in non-hypertensive rats [17]. This preserved response to NogoA antibodies suggests that growth factor abnormalities may not be clinically relevant. Whether this conclusion is true for conditions of prolonged arterial hypertension, which in humans causes cerebral microangiopathy, remains to be shown.

\section{Compromised Brain Remodeling Associated with} Hyperlipidemia

Hyperlipidemia reduces angiogenesis [86] and promotes blood-brain barrier permeability [87]. These vascular changes involve multiple players, namely reduced endothelial NO synthase (eNOS) activity, excessive lipid peroxidation, and overactivation of matrix metalloproteinases (MMP)-2 and -9 , calpain-1/2 and the small RhoGTPase RhoA [86, 87]. In rats subjected to focal cerebral ischemia, vitamin $\mathrm{B} 3$ administration, which elevates high-density lipoprotein (HDL) and thereby reduces serum cholesterol, increased angiogenesis, the expression of VEGF and angiopoietin-1, and enhanced the phosphorylation (i.e., activation) of eNOS and the angiopoietin-1 receptor Tie2, thus improving neurological recovery [88]. After focal cerebral ischemia in rats, vitamin B3 supplementation enhanced white matter remodeling in the peri-infarct tissue, increased BDNF and TrkB levels and downregulated Nogo receptor levels [89]. These observations suggest that the pathophysiological sequelae associated with hyperlipidemia are amenable to therapeutic interventions, and that lipid-modulating strategies may particularly be promising to achieve this purpose.

As long as hyperlipidemia persists, brain responses to restorative therapies are nonetheless compromised, as suggested by a recent study, in which the effects of a cholesterol-rich diet-induced hyperlipidemia on VEGF-induced cerebral angiogenesis, post-ischemic regional CBF and recovery of the cerebral energy state were analyzed [90]. In this study, impaired angiogenesis was noticed following VEGF treatment in hyperlipidemic mice. The im-

Neurological Recovery in the Post-Acute Stroke Phase paired angiogenesis was associated with blunted regional CBF responses and secondary breakdown of the energy state, once animals were subsequently exposed to focal cerebral ischemia [90]. Subsequent in vitro studies showed that upon exposure to low density lipoproteins (LDL), which mediate most of the detrimental effects of hyperlipidemia, VEGF's receptor VEGFR2 was internalized by endothelial cells and degraded via the late endosome in a syntaxin-16-dependent manner [91]. As a consequence of the LDL exposure, VEGFR2 phosphorylation and downstream signaling were compromised. These data questioned the concept of therapeutic angiogenesis, which aims at restoring blood flow in advanced stages of atherosclerosis. Patients with advanced intracranial atherosclerosis particularly often exhibit hyperlipidemia $[92,93]$.

\section{Compromised Brain Remodeling Associated with Diabetes}

That impaired glucose control has detrimental effects for plasticity-promoting therapies was recently shown in rats suffering from streptozotocin-induced type I diabetes. Paradoxically, delivery of BMSC did not improve neurological recovery in diabetic rats, but increased mortality, blood-brain barrier leakage, and brain hemorrhage [94]. Besides, excessive angiogenesis was noted in diabetic rats receiving BMSC; this was associated with cerebral arteriole narrowing and neointima formation inside the internal carotid artery [94]. In histochemical studies, increased macrophage accumulation was noted in blood vessels of diabetic rats that had been treated with BMSC [94]. These abnormalities were attributed to an increased angiogenin expression in the brain and brain-supplying arteries of diabetic rats. The authors suggest that early BMSC treatment within $24 \mathrm{~h}$ after stroke onset should not be considered in diabetic patients. Further studies identifying the conditions of efficacy and safety of cell-based therapy for diabetic patients are warranted.

In contrast to BMSC, delivery of vitamin B3 was shown to enhance neurological recovery in streptozotocin-induced type I diabetes [95]. In line with the improved recovery, enhanced sprouting of motor cortical axons across the midline in the direction of the lesion-sided motor cortex was observed. When combined with BMSC, vitamin B3 delivery reversed the increased brain hemorrhage, and decreased blood-brain barrier leakage and arteriosclerosis-like changes that were induced by BMSC [96]. These results suggest that stroke patients suffering from diabetes might benefit from vitamin B3, whereas BMSC treatment should, if at all, be considered with great caution in diabetic patients. 


\section{Consequences for Translation to Human Patients}

The benefits of neurorestorative therapies in experimental studies on ischemic stroke are evident. With restorative therapies, we can essentially treat all patients, and we are not hampered by reduced tissue perfusion, which restricts the delivery of neuroprotective agents, nor the necessity of rapid intervention, within hours after stroke. Yet, restorative therapies require stringent proofof-concept studies, translating in a one-to-one manner experimental findings to the patient. If not properly translated, this promising approach, for which compelling experimental data have been accrued, will meet a premature end within a myriad of failed neuroprotective trials.

Over a long period of time, the lack of potential confounders in young, otherwise healthy laboratory animals was strongly appreciated in the stroke field. Reproducible models inducing uniform stroke lesions were developed in genetically inbred animal strains (mostly rodents), allowing insights into post-ischemic remodeling and neurological recovery processes even in small numbers of animals. With these models, the therapeutic potential of neurorestorative treatments was identified. The recent insights that responses to neurorestorative therapies may differ depending on age, risk factors and co-morbidities undoubtedly raise the need for evaluating recovery processes under conditions more closely resembling those in human patients. This knowledge increases the complexity of research on neurorestorative therapies.

Although post-stroke neurorestoration identified in animals appear relevant to humans, testing restorative therapy in the human is even more complex than in the laboratory animal [4]. While experimental studies make use of defined pathophysiological states, the clinic is even much more diverse. Stroke patients vary considerably in age and genetic background, as well as in the etiology, localization, and size of brain infarcts. Thus, the question arises whether clinical neurorestoration studies should enroll all stroke patients independent of genetic backgrounds, stroke localization and size, or whether studies should focus on patients within more defined subgroups. Heterogeneous patient populations may be a reason for the failure of therapeutic interventions as they may mask the therapeutic benefits seen in certain subgroups.

A number of conditions have been identified in animal studies, which potentially undermine neurorestorative therapies, among which hyperlipidemia and diabetes are particularly noteworthy. Future studies should carefully mimic such conditions in preparation for clinical trials. Thus, patients with certain risk factor profiles, for example, poorly controlled diabetes, should possibly be excluded from clinical trials. Risk factors should rigorously be treated based on existing therapeutic guidelines. The overriding message of this minireview is a strong credo in the potential of neurorestorative therapies. A robust substrate for restorative processes is present in the majority of stroke patients, even the elderly. This endogenous recovery potential offers itself for therapeutic use.

\section{Acknowledgments}

This work was supported by the German Research Foundation (HE3173/2-1, HE3173/2-2 and HE3173/3-1; to D.M.H.) and the National Institutes of Health (NIH) (R01AG037506; to M.C.). We gratefully acknowledge Dr. Yi Li for generating the figure employed in this manuscript.

\section{Disclosure Statement}

None.

\section{References}

1 Savitz SI, Fisher M: Future of neuroprotection for acute stroke: in the aftermath of the SAINT trials. Ann Neurol 2007;61:396-402.

2 Ginsberg MD: Neuroprotection for ischemic stroke: past, present and future. Neuropharmacology 2008;55:363-389.

-3 Hermann DM, Zechariah A: Implications of vascular endothelial growth factor for postischemic neurovascular remodeling. J Cereb Blood Flow Metab 2009;29:1620-1643.

4 Hermann DM, Chopp M: Promoting brain remodelling and plasticity for stroke recovery: therapeutic promise and potential pitfalls of clinical translation. Lancet Neurol 2012;11: 369-380.

5 Reitmeir R, Kilic E, Kilic U, Bacigaluppi M, ElAli A, Salani G, Pluchino S, Gassmann M, Hermann DM: Post-acute delivery of erythropoietin induces stroke recovery by promoting perilesional tissue remodelling and contralesional pyramidal tract plasticity. Brain 2011;134:84-99.

6 Andres RH, Horie N, Slikker W, Keren-Gill H, Zhan K, Sun G, Manley NC, Pereira MP, Sheikh LA, McMillan EL, Schaar BT, Svendsen CN, Bliss TM, Steinberg GK: Human neu- ral stem cells enhance structural plasticity and axonal transport in the ischaemic brain. Brain 2011;134:1777-1789.

7 Clarkson AN, Huang BS, Macisaac SE, Mody I, Carmichael ST: Reducing excessive GABAmediated tonic inhibition promotes functional recovery after stroke. Nature 2010;468: 305-309.

-8 Clarkson AN, Overman JJ, Zhong S, Mueller R, Lynch G, Carmichael ST: AMPA receptorinduced local brain-derived neurotrophic factor signaling mediates motor recovery after stroke. J Neurosci 2011;31:3766-3775. 
9 Hermann DM, ElAli A: The abluminal endothelial membrane in neurovascular remodeling in health and disease. Sci Signal 2012; 5:re4.

10 Rosell A, Lo EH: Multiphasic roles for matrix metalloproteinases after stroke. Curr Opin Pharmacol 2008;8:82-89.

-11 Bacigaluppi M, Pluchino S, Peruzzotti-Jametti L, Kilic E, Kilic U, Salani G, Brambilla E, West MJ, Comi G, Martino G, Hermann DM: Delayed post-ischaemic neuroprotection following systemic neural stem cell transplantation involves multiple mechanisms. Brain 2009;132:2239-2251.

-12 Andres RH, Horie N, Slikker W, Keren-Gill H, Zhan K, Sun G, Manley NC, Pereira MP, Sheikh LA, McMillan EL, Schaar BT, Svendsen CN, Bliss TM, Steinberg GK: Human neural stem cells enhance structural plasticity and axonal transport in the ischaemic brain. Brain 2011;134:1777-1789.

13 Zhang R, Wang Y, Zhang L, Zhang Z, Tsang W, Lu M, Zhang L, Chopp M: Sildenafil induces neurogenesis and promotes functional recovery after stroke in rats. Stroke 2002;33: 2675-2680.

-14 Markus TM, Tsai SY, Bollnow MR, Farrer RG, O'Brien TE, Kindler-Baumann DR, Rausch M, Rudin M, Wiessner C, Mir AK, Schwab ME, Kartje GL: Recovery and brain reorganization after stroke in adult and aged rats. Ann Neurol 2005;58:950-953.

15 Shen LH, Li Y, Chen J, Zacharek A, Gao Q, Kapke A, Lu M, Raginski K, Vanguri P, Smith A, Chopp M: Therapeutic benefit of bone marrow stromal cells administered 1 month after stroke. J Cereb Blood Flow Metab 2007; 27:6-13.

-16 Tsai SY, Papadopoulos CM, Schwab ME, Kartje GL: Delayed anti-nogo-a therapy improves function after chronic stroke in adult rats. Stroke 2011;42:186-190.

-17 Wiessner C, Bareyre FM, Allegrini PR, Mir AK, Frentzel S, Zurini M, Schnell L, Oertle T, Schwab ME: Anti-Nogo-A antibody infusion 24 hours after experimental stroke improved behavioral outcome and corticospinal plasticity in normotensive and spontaneously hypertensive rats. J Cereb Blood Flow Metab 2003;23:154-165.

18 Liu Z, Li Y, Zhang RL, Cui Y, Chopp M: Bone marrow stromal cells promote skilled motor recovery and enhance contralesional axonal connections after ischemic stroke in adult mice. Stroke 2011;42:740-744.

19 Li L, Jiang Q, Ding G, Zhang L, Zhang ZG, Li Q, Panda S, Kapke A, Lu M, Ewing JR, Chopp M: MRI identification of white matter reorganization enhanced by erythropoietin treatment in a rat model of focal ischemia. Stroke 2009;40:936-941.

20 Jiang Q, Zhang ZG, Chopp M: MRI evaluation of white matter recovery after brain in jury. Stroke 2010;41:S112-S113.

-21 Reitmeir R, Kilic E, Reinboth BS, Guo Z, ElAli A, Zechariah A, Kilic Ü, Hermann DM: Vascular endothelial growth factor induces con- tralesional corticobulbar plasticity and functional neurological recovery in the ischemic brain. Acta Neuropathol 2012;123:273-284.

22 Herz J, Reitmeir R, Hagen SI, Reinboth BS, Guo Z, Zechariah A, Elali A, Doeppner TR, Bacigaluppi M, Pluchino S, Kilic U, Kilic E, Hermann DM: Intracerebroventricularly delivered VEGF promotes contralesional corticorubral plasticity after focal cerebral ischemia via mechanisms involving anti-inflammatory actions. Neurobiol Dis 2012;45: 1077-1085.

23 Papadopoulos CM, Tsai SY, Alsbiei T, O'Brien TE, Schwab ME, Kartje GL: Functional recovery and neuroanatomical plasticity following middle cerebral artery occlusion and IN-1 antibody treatment in the adult rat. Ann Neurol 2002;51:433-441.

24 Papadopoulos CM, Tsai SY, Guillen V, Ortega J, Kartje GL, Wolf WA: Motor recovery and axonal plasticity with short-term amphetamine after stroke. Stroke 2009;40:294-302.

25 Freund P, Schmidlin E, Wannier T, Bloch J, Mir A, Schwab ME, Rouiller EM: Nogo-Aspecific antibody treatment enhances sprouting and functional recovery after cervical lesion in adult primates. Nat Med 2006;12:790792.

26 Shen LH, Li Y, Chen J, Cui Y, Zhang C, Kapke A, Lu M, Savant-Bhonsale S, Chopp M: Oneyear follow-up after bone marrow stromal cell treatment in middle-aged female rats with stroke. Stroke 2007;38:2150-2156.

27 Zhang RL, Zhang Z, Zhang L, Wang Y, Zhang C, Chopp M: Delayed treatment with sildenafil enhances neurogenesis and improves functional recovery in aged rats after focal cerebral ischemia. J Neurosci Res 2006;83: 1213-1219.

28 Forsythe JA, Jiang BH, Iyer NV, Agani F, Leung SW, Koos RD, Semenza GL: Activation of vascular endothelial growth factor gene transcription by hypoxia-inducible factor 1 . Mol Cell Biol 1996;16:4604-4613.

29 Marti HJ, Bernaudin M, Bellail A, Schoch H, Euler M, Petit E, Risau W: Hypoxia-induced vascular endothelial growth factor expression precedes neovascularization after cerebral ischemia. Am J Pathol 2000;156:965-976.

30 Kilic E, Kilic U, Wang Y, Bassetti CL, Marti HH, Hermann DM: The phosphatidylinositol-3 kinase/Akt pathway mediates VEGF's neuroprotective activity and induces blood brain barrier permeability after focal cerebral ischemia. FASEB J 2006;20:1185-1187.

31 Ridgway J, Zhang G, Wu Y, Stawicki S, Liang WC, Chanthery Y, Kowalski J, Watts RJ, Callahan C, Kasman I, Singh M, Chien M, Tan C, Hongo JA, de Sauvage F, Plowman G, Yan M: Inhibition of Dll4 signalling inhibits tumour growth by deregulating angiogenesis. Nature 2006;444:1083-1087.

32 Hellström M, Phng LK, Hofmann JJ, Wallgard E, Coultas L, Lindblom P, Alva J, Nilsson AK, Karlsson L, Gaiano N, Yoon K, Rossant J, Iruela-Arispe ML, Kalén M, Gerhardt H, Betsholtz C: Dll4 signalling through Notch1 reg- ulates formation of tip cells during angiogenesis. Nature 2007;445:776-780.

33 Al Haj Zen A, Oikawa A, Bazan-Peregrino M, Meloni M, Emanueli C, Madeddu P: Inhibition of delta-like-4-mediated signaling impairs reparative angiogenesis after ischemia. Circ Res 2010;107:283-293.

34 Takeshita K, Satoh M, Ii M, Silver M, Limbourg FP, Mukai Y, Rikitake Y, Radtke F, Gridley T, Losordo DW, Liao JK: Critical role of endothelial Notch1 signaling in postnatal angiogenesis. Circ Res 2007;100:70-78.

35 Zacharek A, Chen J, Cui X, Yang Y, Chopp M: Simvastatin increases notch signaling activity and promotes arteriogenesis after stroke. Stroke 2009;40:254-260.

36 Wang Y, Kilic E, Kilic U, Weber B, Bassetti CL, Marti HH, Hermann DM: VEGF overexpression induces post-ischaemic neuroprotection, but facilitates haemodynamic steal phenomena. Brain 2005;128:52-63.

37 Zechariah A, ElAli A, Doeppner TR, Jin F, Hasan MR, Helfrich I, Mies G, Hermann DM: Vascular endothelial growth factor promotes pericyte coverage of brain capillaries, improves cerebral blood flow during subsequent focal cerebral ischemia, and preserves the metabolic penumbra. Stroke 2013;44:1690-1697.

38 Zhang RL, Zhang Z, Zhang L, Wang Y, Zhang C, Chopp M: Delayed treatment with sildenafil enhances neurogenesis and improves functional recovery in aged rats after focal cerebral ischemia. J Neurosci Res 2006;83: 1213-1219.

39 Zhang RL, Zhang ZG, Zhang L, Chopp M: Proliferation and differentiation of progenitor cells in the cortex and the subventricular zone in the adult rat after focal cerebral ischemia. Neuroscience 2001;105:33-41.

40 Arvidsson A, Collin T, Kirik D, Kokaia Z, Lindvall O: Neuronal replacement from endogenous precursors in the adult brain after stroke. Nat Med 2002;8:963-970.

41 Chen J, Zhang ZG, Li Y, Wang Y, Wang L, Jiang H, Zhang C, Lu M, Katakowski M, Feldkamp CS, Chopp M: Statins induce angiogenesis, neurogenesis, and synaptogenesis after stroke. Ann Neurol 2003;53:743-751.

42 Thored P, Wood J, Arvidsson A, Cammenga J, Kokaia Z, Lindvall O: Long-term neuroblast migration along blood vessels in an area with transient angiogenesis and increased vascularization after stroke. Stroke 2007;38:3032-3039.

43 Zhang RL, Chopp M, Gregg SR, Toh Y, Roberts C, Letourneau Y, Buller B, Jia L, P Nejad Davarani S, Zhang ZG: Patterns and dynamics of subventricular zone neuroblast migration in the ischemic striatum of the adult mouse. J Cereb Blood Flow Metab 2009;29: 1240-1250.

44 Teng $\mathrm{H}$, Zhang ZG, Wang L, Zhang RL, Zhang L, Morris D, Gregg SR, Wu Z, Jiang A, Lu M, Zlokovic BV, Chopp M: Coupling of angiogenesis and neurogenesis in cultured endothelial cells and neural progenitor cells after stroke. J Cereb Blood Flow Metab 2008; 28:764-771. 
-45 Lee ST, Chu K, Jung KH, Kim SJ, Kim DH, Kang KM, Hong NH, Kim JH, Ban JJ, Park HK, Kim SU, Park CG, Lee SK, Kim M, Roh JK: Antiinflammatory mechanism of intravascular neural stem cell transplantation in haemorrhagic stroke. Brain 2008;131:616-629.

-46 Pannasch U, Vargova L, Reingruber J, Ezan P, Holcman D, Giaume C, Sykova E, Rouach N: Astroglial networks scale synaptic activity and plasticity. Proc Natl Acad Sci U S A 2011; 108:8467-8472.

47 ElAli A, Hermann DM: Apolipoprotein E controls ATP-binding cassette transporters in the ischemic brain. Sci Signal 2010;3:ra72.

-48 Spudich A, Kilic E, Xing H, Kilic U, Rentsch $\mathrm{KM}$, Wunderli-Allenspach $\mathrm{H}$, Bassetti CL, Hermann DM: Inhibition of multidrug resistance transporter-1 facilitates neuroprotective therapies after focal cerebral ischemia. Nat Neurosci 2006;9:487-488.

49 McKeon RJ, Jurynec MJ, Buck CR: The chondroitin sulfate proteoglycans neurocan and phosphacan are expressed by reactive astrocytes in the chronic CNS glial scar. J Neurosci 1999; 19:10778-10788.

-50 Morgenstern DA, Asher RA, Fawcett JW: Chondroitin sulphate proteoglycans in the CNS injury response. Prog Brain Res 2002; 137:313-332.

51 Snow DM, Mullins N, Hynds DL: Nervous system-derived chondroitin sulfate proteoglycans regulate growth cone morphology and inhibit neurite outgrowth: a light, epifluorescence, and electron microscopy study. Microsc Res Tech 2001;54:273-286.

-52 Shen LH, Li Y, Gao Q, Savant-Bhonsale S, Chopp M: Down-regulation of neurocan expression in reactive astrocytes promotes axonal regeneration and facilitates the neurorestorative effects of bone marrow stromal cells in the ischemic rat brain. Glia 2008;56: 1747-1754.

53 Gao Q, Li Y, Chopp M: Bone marrow stromal cells increase astrocyte survival via upregulation of phosphoinositide 3-kinase/threonine protein kinase and mitogen-activated protein kinase kinase/extracellular signal-regulated kinase pathways and stimulate astrocyte trophic factor gene expression after anaerobic insult. Neuroscience 2005;136:123-134.

- 54 Li L, Lundkvist A, Andersson D, Wilhelmsson U, Nagai N, Pardo AC, Nodin C, Stahlberg A, Aprico K, Larsson K, Yabe T, Moons L, Fotheringham A, Davies I, Carmeliet P, Schwartz JP, Pekna M, Kubista M, Blomstrand F, Maragakis N, Nilsson M, Pekny M: Protective role of reactive astrocytes in brain ischemia. J Cereb Blood Flow Metab 2008;28: 468-481.

55 Trendelenburg G, Dirnagl U: Neuroprotective role of astrocytes in cerebral ischemia: focus on ischemic preconditioning. Glia 2005; 50:307-320.

-56 Shen LH, Xin H, Li Y, Zhang RL, Cui Y, Zhang L, Lu M, Zhang ZG, Chopp M: Endogenous tissue plasminogen activator mediates bone marrow stromal cell-induced neurite remod- eling after stroke in mice. Stroke 2011;42: 459-464.

57 Xin H, Li Y, Shen LH, Liu X, Hozeska-Solgot A, Zhang RL, Zhang ZG, Chopp M: Multipotent mesenchymal stromal cells increase tPA expression and concomitantly decrease PAI-1 expression in astrocytes through the sonic hedgehog signaling pathway after stroke (in vitro study). J Cereb Blood Flow Metab 2011; 31:2181-2188.

58 Kasai K, Takahashi M, Osumi N, Sinnarajah S, Takeo T, Ikeda H, Kehrl JH, Itoh G, Arnheiter H: The G12 family of heterotrimeric G proteins and Rho GTPase mediate Sonic hedgehog signalling. Genes Cells 2004;9:4958.

59 Ding X, Li Y, Liu Z, Zhang J, Cui Y, Chen X, Chopp M: The sonic hedgehog pathway mediates brain plasticity and subsequent functional recovery after bone marrow stromal cell treatment of stroke in mice. J Cereb Blood Flow Metab 2013, in press.

60 Cayuso J, Martí E: Morphogens in motion: growth control of the neural tube. J Neurobiol 2005;64:376-387.

61 Machold R, Hayashi S, Rutlin M, Muzumdar MD, Nery S, Corbin JG, Gritli-Linde A, Dellovade T, Porter JA, Rubin LL, Dudek H, McMahon AP, Fishell G: Sonic hedgehog is required for progenitor cell maintenance in telencephalic stem cell niches. Neuron 2003;39: 937-950.

62 Stecca B, Ruiz i Altaba A: Brain as a paradigm of organ growth: Hedgehog-Gli signaling in neural stem cells and brain tumors. J Neurobiol 2005;64:476-490.

63 Lee HY, Hwang IY, Im H, Koh JY, Kim YH: Non-proteolytic neurotrophic effects of tissue plasminogen activator on cultured mouse cerebrocortical neurons. J Neurochem 2007; 101:1236-1247.

64 Wind T, Hansen M, Jensen JK, Andreasen PA: The molecular basis for anti-proteolytic and non-proteolytic functions of plasminogen activator inhibitor type-1: roles of the reactive centre loop, the shutter region, the flexible joint region and the small serpin fragment. Biol Chem 2002;383:21-36.

65 Manwani B, Liu F, Xu Y, Persky R, Li J, McCullough LD: Functional recovery in aging mice after experimental stroke. Brain Behav Immun 2011;25:1689-1700.

66 Popa-Wagner A, Badan I, Walker L, Groppa S, Patrana N, Kessler C: Accelerated infarct development, cytogenesis and apoptosis following transient cerebral ischemia in aged rats. Acta Neuropathol 2007;113:277-293.

67 Lindner MD, Gribkoff VK, Donlan NA, Jones TA: Long-lasting functional disabilities in middle-aged rats with small cerebral infarcts. J Neurosci 2003;23:10913-10922.

68 Buchhold B, Mogoanta L, Suofu Y, Hamm A, Walker L, Kessler Ch, Popa-Wagner A: Environmental enrichment improves functional and neuropathological indices following stroke in young and aged rats. Restor Neurol Neurosci 2007;25:467-484.
69 Popa-Wagner A, Buga AM, Kokaia Z: Perturbed cellular response to brain injury during aging. Ageing Res Rev 2011;10:71-79.

70 Calamante F, Thomas DL, Pell GS, Wiersma J, Turner R: Measuring cerebral blood flow using magnetic resonance imaging techniques. J Cereb Blood Flow Metab 1999;19:701-735.

71 Carter AR, Shulman GL, Corbetta M: Why use a connectivity-based approach to study stroke and recovery of function? Neuroimage 2012;62:2271-2280.

72 Zhang L, Zhang RL, Wang Y, Zhang C, Zhang ZG, Meng H, Chopp M: Functional recovery in aged and young rats after embolic stroke: treatment with a phosphodiesterase type 5 inhibitor. Stroke 2005;36:847-852

73 Gillani RL, Tsai SY, Wallace DG, O'Brien TE, Arhebamen E, Tole M, Schwab ME, Kartje GL: Cognitive recovery in the aged rat after stroke and anti-Nogo-A immunotherapy. Behav Brain Res 2010;208:415-424.

74 Li S, Overman JJ, Katsman D, Kozlov SV, Donnelly CJ, Twiss JL, Giger RJ, Coppola G, Geschwind DH, Carmichael ST: An age-related sprouting transcriptome provides molecular control of axonal sprouting after stroke. Nat Neurosci 2010;13:1496-1504.

75 Darsalia V, Heldmann U, Lindvall O, Kokaia Z: Stroke-induced neurogenesis in aged brain. Stroke 2005;36:1790-1795.

-76 Gao P, Shen F, Gabriel RA, Law D, Yang E, Yang GY, Young WL, Su H: Attenuation of brain response to vascular endothelial growth factor-mediated angiogenesis and neurogenesis in aged mice. Stroke 2009;40:3596-3600.

77 Zhang RL, Zhang Z, Zhang L, Wang Y, Zhang C, Chopp M: Delayed treatment with sildenafil enhances neurogenesis and improves functional recovery in aged rats after focal cerebral ischemia. J Neurosci Res 2006;83:1213-1219.

78 Popa-Wagner A, Stöcker K, Balseanu AT, Rogalewski A, Diederich K, Minnerup J, Margaritescu C, Schäbitz WR: Effects of granulocyte-colony stimulating factor after stroke in aged rats. Stroke 2010;41:1027-1031.

79 Popa-Wagner A, Dinca I, Yalikun S, Walker L, Kroemer H, Kessler C: Accelerated delimitation of the infarct zone by capillary-derived nestin-positive cells in aged rats. Curr Neurovasc Res 2006;3:3-13.

80 Oster-Granite ML, McPhie DL, Greenan J, Neve RL: Age dependent neuronal and synaptic degeneration in mice transgenic for the $\mathrm{C}$ terminus of the amyloid precursor protein. J Neurosci 1996;16:6732-6741.

81 Badan I, Dinca I, Buchhold B, Suofu Y, Walker L, Gratz M, Platt D, Kessler CH, PopaWagner A: Accelerated accumulation of $\mathrm{N}$ and C-terminal beta APP fragments and delayed recovery of microtubule-associated protein 1B expression following stroke in aged rats. Eur J Neurosci 2004;9:2270-2280.

82 Zhao Z, Ksiezak-Reding H, Wang J, Pasinetti GM: Expression of tau reduces secretion of Abeta without altering the amyloid precursor protein content in CHOsw cells. FEBS Lett 2005;579:2119-2124. 
83 Goldstein LB, Adams R, Alberts MJ, Appel LJ, Brass LM, Bushnell CD, et al: Primary prevention of ischemic stroke: a guideline from the American Heart Association/American Stroke Association Stroke Council: cosponsored by the Atherosclerotic Peripheral Vascular Disease Interdisciplinary Working Group; Cardiovascular Nursing Council; Clinical Cardiology Council; Nutrition, Physical Activity, and Metabolism Council; and the Quality of Care and Outcomes Research Interdisciplinary Working Group: the American Academy of Neurology affirms the value of this guideline. Stroke 2006;37:1583-1633.

84 Adams HP Jr, del Zoppo G, Alberts MJ, Bhatt DL, Brass L, Furlan A, et al: Guidelines for the early management of adults with ischemic stroke: a guideline from the American Heart Association/American Stroke Association Stroke Council, Clinical Cardiology Council, Cardiovascular Radiology and Intervention Council, and the Atherosclerotic Peripheral Vascular Disease and Quality of Care Outcomes in Research Interdisciplinary Working Groups: The American Academy of Neurology affirms the value of this guideline as an educational tool for neurologists. Circulation 2007;115:e478-e534.

85 Hennigan A, Callaghan CK, Kealy J, Rouine J, Kelly AM: Deficits in LTP and recognition memory in the genetically hypertensive rat are associated with decreased expression of neurotrophic factors and their receptors in the dentate gyrus. Behav Brain Res 2009;197: 371-377.
86 Duan J, Murohara T, Ikeda H, Katoh A, Shintani S, Sasaki K, Kawata H, Yamamoto N, Imaizumi T: Hypercholesterolemia inhibits angiogenesis in response to hindlimb ischemia: nitric oxide-dependent mechanism. Circulation 2000;102:III370- III376.

87 ElAli A, Doeppner TR, Zechariah A, Hermann DM: Increased blood-brain barrier permeability and brain edema after focal cerebral ischemia induced by hyperlipidemia: role of lipid peroxidation and calpain-1/2, matrix metalloproteinase- $2 / 9$, and rhoA overactivation. Stroke 2011;42:3238-3244.

88 Chen J, Cui X, Zacharek A, Jiang H, Roberts C, Zhang C, Lu M, Kapke A, Feldkamp CS, Chopp M: Niaspan increases angiogenesis and improves functional recovery after stroke. Ann Neurol 2007;62:49-58.

-89 Cui X, Chopp M, Zacharek A, Roberts C, Buller B, Ion M, Chen J: Niacin treatment of stroke increases synaptic plasticity and axon growth in rats. Stroke 2010;41:2044-2049.

90 Zechariah A, ElAli A, Hagemann N, Jin F, Doeppner TR, Helfrich I, Mies G, Hermann DM: Hyperlipidemia attenuates vascular endothelial growth factor-induced angiogenesis, impairs cerebral blood flow, and disturbs stroke recovery via decreased pericyte coverage of brain endothelial cells. Arterioscler Thromb Vasc Biol 2013;33:1561-1567.
91 Jin F, Hagemann N, Brockmeier U, Schäfer ST, Zechariah A, Hermann DM: LDL attenuates VEGF-induced angiogenesis via mechanisms involving VEGFR2 internalization and degradation following endosome-trans-Golgi network trafficking. Angiogenesis 2013;16: 625-637.

92 Turan TN, Makki AA, Tsappidi S, Cotsonis G, Lynn MJ, Cloft HJ, Chimowitz MI; WASID Investigators: Risk factors associated with severity and location of intracranial arterial stenosis. Stroke 2010;41:1636-1640.

$\checkmark 93$ Park JH, Hong KS, Lee EJ, Lee J, Kim DE: High levels of apolipoprotein B/AI ratio are associated with intracranial atherosclerotic stenosis. Stroke 2011;42:3040-3046.

94 Chen J, Ye X, Yan T, Zhang C, Yang XP, Cui X, Cui Y, Zacharek A, Roberts C, Liu X, Dai X, Lu M, Chopp M: Adverse effects of bone marrow stromal cell treatment of stroke in diabetic rats. Stroke 2011;42:35513558.

95 Yan T, Chopp M, Ye X, Liu Z, Zacharek A, Cui Y, Roberts C, Buller B, Chen J: Niaspan increases axonal remodeling after stroke in type 1 diabetes rats. Neurobiol Dis 2012;46:157164.

$\$ 66$ Yan T, Ye X, Chopp M, Zacharek A, Ning R, Venkat P, Roberts C, Lu M, Chen J: Niaspan attenuates the adverse effects of bone marrow stromal cell treatment of stroke in type one diabetic rats. PLoS One 2013;8:e81199. 